\title{
Take a Walk! Innovative Programming from Winnipeg Public Library
}

Kirsten Wurmann, Librarian and Branch Head, West End

Winnipeg Public Library

kwurmann@winnipeg.ca

\section{Abstract}

Historical walks, literary walks, and walking book clubs-learn how Winnipeg Public Library is taking it outside. Rebecca Solnit, in her book Wanderlust: A History of Walking, writes: "Walking shares with making and working that crucial element of engagement of the body and the mind with the world, of knowing the world through the body and the body through the world."

As libraries work hard to share knowledge with their communities and to engage patrons in new ways, this presentation addresses the practicalities of creating a program that speaks uniquely to your own neighbourhood and patrons: Learn about the walking programs offered by various Winnipeg Public Library branches; recognize the benefits of these programs and how they can relate to library programming goals and strategic plans; and identify resources that can help you develop your own walking programs.

This summary is based on a poster presentation given at the annual Ontario Library Association Super Conference held in Toronto, Ontario on January 27-30, 2016.

\section{Keywords}

Public librarianship; programming; community engagement

\section{Introduction}

Walking: many can do it and nobody is an expert. Walking is an exercise in simplicity (Solnit, 2000). For the majority of us, walking is a basic human activity requiring little mental effort and permitting our minds to be free to wander. According to some, walking fosters a mental state ideal for "innovative ideas and strokes of insight" (Jabr, 2014, para. 6).

Libraries: many communities have them and all are welcome. Libraries are institutions of knowledge, freedom, and access. Nowadays, libraries are further broadening their impact, going beyond their physical branches and increasingly becoming hubs for 
community connections by embracing and developing unique programming opportunities for their patrons.

The humble act of walking is experiencing a renaissance of sorts, with recent books and articles extolling its virtues (please see "Further Reading" for a selection of materials). Walking will make you healthier, more creative, more productive, and more communicative. (Wong, 2014). The Winnipeg Public Library (WPL) was interested in exploring the potential relationship between walking and the library-could it develop into a unique literary movement or perhaps cultivate what Ralph Waldo Emerson described as "gymnastics for the mind"? (Oriet, 2016, p. 2). With all this in mind, the WPL decided to "take it outside" by incorporating historical walks, literary walks, and walking book clubs into its programming. Our unique approach has been popular and has permitted us to engage with our patrons in new ways, all the while injecting literacy and information access into our programs.

\section{What We Did and How We Did It}

As a first step, you need to decide if your program will be created from scratch or run with a community partner. Depending on your needs and resources, you may find one approach better suited to your library.

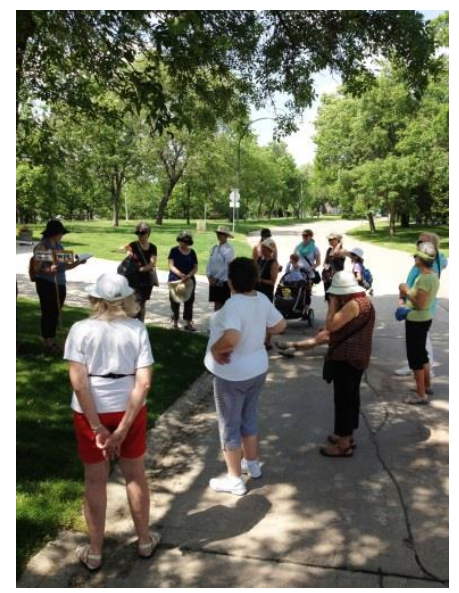

Figure 1.

\section{Historical Walks and Garden Tours}

At WPL, our historical walks provide the opportunity for us to collaborate with local nonprofit organizations, such as historical museums, that have significant expertise in the history of the community. For instance, the St James-Assiniboia branch's Walk about Bruce Park programming is delivered by summer students employed by the local historical society. This provides students with the opportunity to learn about the history of their community and the chance to actively participate in the dissemination of that knowledge during the interpretive walks. Partnerships with these types of non-profits also allow the library to give its support and spread the word about a 
community historical organization, while at the same time create exposure for its own programming. Branch head, Reegan Breu, described the walk as:

[...] a celebration of this community and its history. Many participants in the walk have been members of the community who were unfamiliar with this part of its history. They have been so happy to learn more about where they live.

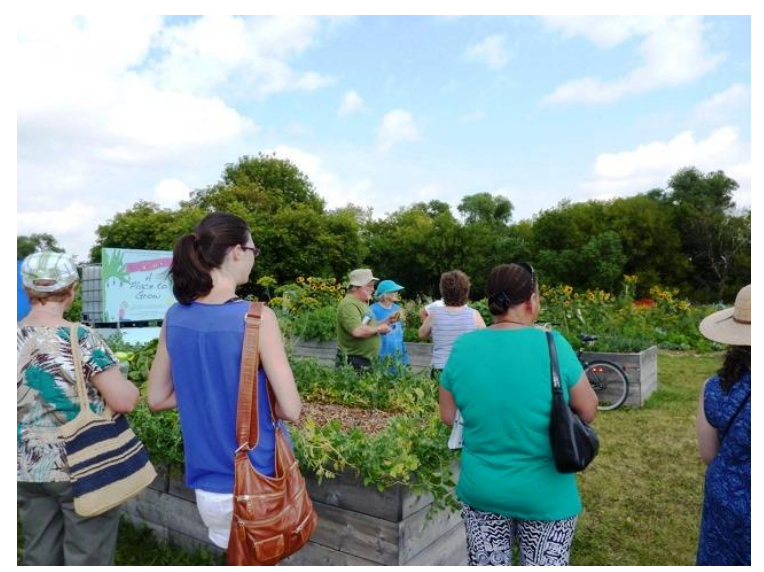

Figure 2.

The garden tours offered at the WPL's Osbourne branch provide other example of a successful collaboration between the library and local organizations. Our popular gardening walks are organized in partnership with community cooperatives and local community centres. These walks usually begin at the library with a brief talk accompanied by library books and resources that are shared with the participants. The program then continues outside with a walk to visit local gardens, showcasing techniques discussed in the library talk, such as community or vertical gardening. Feedback from the participants has been very positive. One participant remarked: "I found this presentation both informational and exciting. I was unaware of this work hidden away within such close proximity to where I pass. Thank you!"

\section{Literary Walks}

Literary walks are another type of program that can also be established in partnership with community organizations; they can also be developed in-house as was done at the WPL's Westwood branch. Westwood Library is conveniently situated in a neighbourhood made up of streets with literary names. Keats Way, Shakespeare Bay, and Dickens Drive are all within easy walking distance of the library and provide for some wonderful inspiration. Library staff compiled interesting anecdotes and biographical information about each writer, poet, or playwright behind the street names. They also chose accompanying poems, short stories, or soliloquies that, along with the fact compilations, were recited and shared with the participants during their literary walks. After one of the walks, an enthusiastic participant expressed the following:

"This was a well organized and informative walk which reawakened an interest in me in the poets and poetry of my long ago high school English classes." 


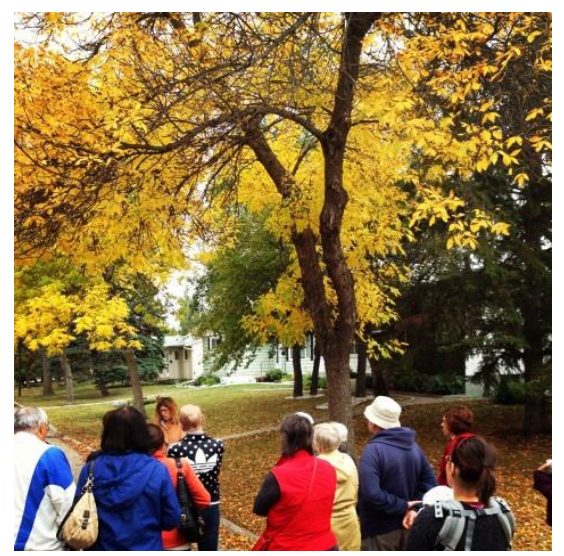

Figure 3.

Of course, not all literary walks will have such fortuitous street names. Other WPL branches are planning walks that will incorporate readings relating to prominent community members, landmarks, or even natural elements (for instance, a poem by Wordsworth could perhaps be recited in front of a garden of daffodils).

\section{Walking Book Clubs}

Two different walking book clubs have been offered at WPL and each branch caters the program to the needs of the walkers and their particular library. Charleswood branch offers a monthly book club (winter months aside) where a library staff member and patrons walk and talk about the book chosen for that particular month. Books have included: Wild by Cheryl Strayed and $A$ Walk in the Woods by Bill Bryson. Meanwhile, Westwood branch offered their walking book club on Friday mornings for three consecutive weeks in July. Readings were given to participants beforehand that were centred on a theme. For instance, for the theme "literary walking," an essay by Virginia Woolf and a chapter from Pride and Prejudice were given as readings. Library staff and participants walked and talked about the readings and then stopped for water and refreshments at a park for more discussion. Both book clubs were well attended and walkers were enthusiastic about the format. One participant shared the following through the library's official program evaluation form: "Well organized, challenging, and entertaining intellectually yet friendly and NOT intimidating. It was a pleasure to be outdoors, walking and sharing thoughts and ideas on a common theme." 


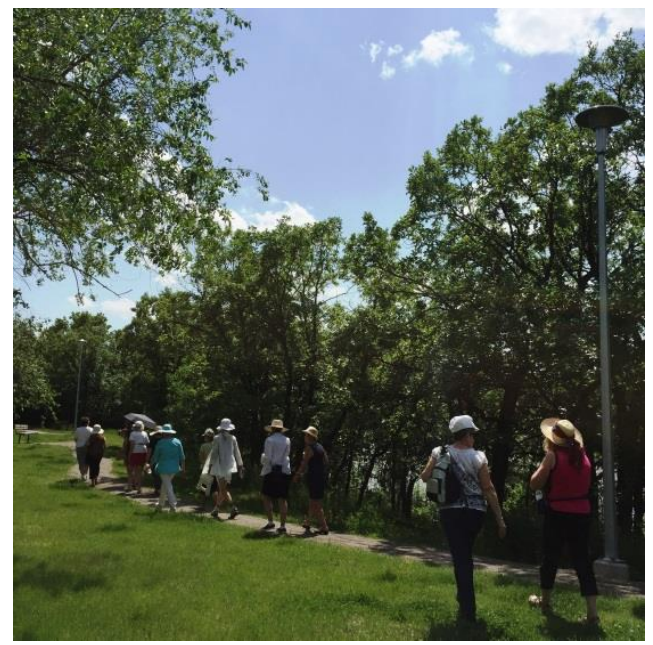

Figure 4.

\section{Tips to Create Your Own Walking Programs}

- Create a basic outline and ask yourself:

○ Where will the group meet? (At the library?)

- Will there be refreshments? (Always a lovely idea!)

- What do we do in case of inclement weather?

- Consult your library's general liability insurance:

- Does it cover off-site activities?

- Have you informed your insurer and checked that the program fits within your liability insurance plan?

$\circ$ Is a waiver required?

- Consider health and safety:

- Use two staff members (one lead, one helper).

- Wear comfortable shoes.

- Dress for the weather.

- Bring (extra) water.

- Carry a cell phone in case help is needed.

- A walk should not be longer than 90 minutes.

- Try not to exceed 20 participants.

- Do an inventory of potential stops (6-10 is optimal) along the walk.

- Learn to speak loudly (or invest in a portable microphone and speaker).

- Do a dry run of the walk ahead of time.

- Try to strike a balance between talking and moving. 
- Connect the walk to the library resources, books and space.

- Be flexible-you might have to adapt on the fly.

- Have FUN.

\section{Works Cited}

Jabr, F. (2014, September 3). Why walking helps us think. The New Yorker.

Oriet, C. (2016, February 26). The gymnasiums of the mind. Philosophy Now.

Solnit, R. (2000). Wanderlust: A history of walking. New York: Penguin Books.

Winnipeg Public Library. (2015). Strategic Plan.

Wong, M. (2014, April 24). Stanford study finds walking improves creativity. Stanford News.

\section{Further Reading}

Gros, F. (2014). A Philosophy of Walking. Verso: London.

Jane's Walk (n.d.). Tips for leading a walk.

Manitoba Historical Society (2013, May 13). How to: Organize a walking tour.

Rhodes, E. (2013, March 9). The birth of the walking book club: How I came to run a book club on Hampstead Heath - and why it works. The Spectator.

Veverka, J. A. (n.d.) Planning interpretive walking tours for communities and related historic districts. 